\title{
INCORPORAÇÃO DE LODO GALVÂNICO E VIDRO SODOCÁLCICO NA PRODUÇÃO DE BLOCOS CERÂMICOS ${ }^{1}$
}

\author{
SODOCALCIUM GLASS AND GALVANIC SLUDGE \\ INCORPORATION IN CERAMIC BLOCKS PRODUCTION
}

\author{
Roseli Black Storck², Daniel Moro Druzian³ e Diogo Kramer Topolski ${ }^{4}$
}

\section{RESUMO}

Este trabalho propõe incorporar um resíduo de lodo galvânico e de vidro sodocálcico na matriz argilosa para fabricação de blocos cerâmicos visando reduzir o descarte destes resíduos transformando-os em matérias primas industriais gerando uma alternativa viável para a sua utilização. As formulações das massas cerâmicas produzidas possuem $0,2,5$ e $10 \%$ em peso do lodo de galvanização empregado e $15 \%$ de vidro sodocálcio. As amostras foram prensadas unixialmente a frio, sinterizadas a $1050{ }^{\circ} \mathrm{C}$ e caracterizadas química e mineralogicamente por difração de raios X (DRX) e espectroscopia no infravermelho (FTIR). As propriedades mecânicas foram obtidas através de ensaio de resistência à flexão em quatro pontos (MOR), porosidade aparente, absorção de água e retração linear. Os resultados confirmam que o principal componente do lodo é o sulfato de cálcio e os testes estruturais mostram que a adição de $2 \%$ de lodo nos blocos cerâmicos manteve a MOR em $20 \mathrm{MPa}$. As massas cerâmicas com maior quantidade de lodo apresentaram uma diminuição na MOR e um aumento considerável de porosidade e absorção de água. Como as análises de DRX e FTIR realizadas após a sinterização não apresentam sulfatos na estrutura do material é possível que a decomposição deste como um gás gere uma alta porcentagem de poros e trincas que são sítios para iniciação da fratura do material.

Palavras-chave: lodo galvanico, material cerâmico, resíduos sólidos.

\section{ABSTRACT}

This work aims to study the incorporation of a galvanoplastic sludge and a sodo-calcium glass in ceramic blocks in order to reduce solid wastes removal. The formulation of the produced ceramic mass contains 0, 2, 5 and $10 \%$ by weight of galvanization sludge incorporating $15 \%$ of sodo-calcium glass. The pieces were cold pressed and sintered at $1050{ }^{\circ} \mathrm{C}$. The samples were characterized mineralogical and chemically by X-Ray diffraction (XRD) and infrared spectroscopy by Fourier transform (IRFT). The mechanical properties were determined by modulus of rupture (MOR), apparent porosity, water absorption and linear shrinkage. The results confirm that the main component of sludge was calcium sulfate and the structural tests reveals that the addition of $2 \%$ of sludge on the ceramic blocks kept the MOR value of $20 \mathrm{MPa}$. The ceramic masses with higher sludge content presented a decreasing in the MOR value and a significant increase in porosity and water absorption.

Keywords: galvanoplastic sludge, solid waste, ceramic material.

\footnotetext{
${ }^{1}$ Pesquisa de trabalho de graduação.

${ }^{2}$ Acadêmico do Curso de Engenharia de Materiais - UFN. E-mail: rosi_storck@hotmail.com

${ }^{3}$ Acadêmico do Programa de Pós-graduação em Nanociências - UFN. E-mail: daniel.moro.druzian@hotmail.com

${ }^{4}$ Orientador. Professor do Curso de Engenharia de Materiais - UFN. E-mail: topolski@gmail.com
} 


\section{INTRODUÇÃO}

Juntamente com o crescimento e desenvolvimento industrial, há também o aumento na produção de resíduos, que muitas vezes é descartado incorretamente causando danos ao meio ambiente. Neste contexto, podem-se destacar os resíduos da indústria galvânica, que produzem grande quantidade de lodo que contém metais pesados (TANAUE et al., 2015).

A indústria galvânica tem como principal objetivo conceder proteção contra a corrosão, onde é realizado um tratamento de superfície por imersão da peça em uma solução que contém íons, formando uma camada de revestimento através da diferença de potencial. Além dos íons residuais dos processos de deposição do metal o efluente de galvanização é composto de ácido sulfúrico ou clorídirico utilizado nas etapas de limpeza do substrato metálico e resíduos retirados do substrato durante esta preparação superficial. Esse processo além de proteger a peça contra a corrosão, também aumenta a vida útil, condutividade e dureza (DA ROCHA et al., 2017).

Os resíduos industriais como o lodo galvânico, são classificados segundo a NBR 10004 (2004) como Resíduos Perigosos (classe I), pois contêm em sua composição química $63 \%$ de água e 37\% de metais pesados e aditivos, que possuem características como: (i) corrosividade, (ii) toxicidade, (iii) inflamabilidade, (iv) patogenicidade e (v) reatividade, que podem causar ou provocar muitos riscos ao meio ambiente e também à saúde humana, se por ventura forem manipulados ou dispostos de uma forma incorreta. Por se tratar de um resíduo perigoso, o lodo galvânico precisa de tratamento diferenciado e de técnicas adequadas para sua disposição final (SANTOS, W. J, 2009).

Pensando nos impactos ambientais causados pelos resíduos industriais galvânicos, e na crescente exigência de implantações de novas políticas ambientais, torna-se cada vez mais necessário a redução destes resíduos e a sua estabilização e o seu reaproveitamento de uma forma economicamente viável para usá-los de uma forma segura, ajudando a eliminar os aterros sanitários e seus elevados custos para sua disposição.

Diante deste cenário, a incorporação de resíduos galvânicos na matriz cerâmica vem sendo amplamente explorada, devido a sua capacidade de imobilizar os metais pesados através da vitrificação, evitando assim a lixiviação dos mesmos para o ambiente, podendo ser usado nas construções civis (DA ROCHA et al., 2017).

O vidro sodocálcico é um material inerte, não cristalino, frágil e não poroso, e pode ser considerado como um isolante térmico e ser usado como carga de enchimento ou de estabilização na matriz cerâmica. Sua presença tende a aumentar a fração de fase vítrea facilitando a imobilização dos íons metálicos (SANTOS, 2009).

No processamento cerâmico dentro dos vários processos industriais utilizados, a prensagem uniaxial se tornou muito utilizada, devido este processo alcançar bastante uniformidade e possuir características básicas que são necessárias ao produto verde sendo fundamental para a qualidade do 
produto cerâmico final. Este processo é fácil e é aplicado em peças com formas simples, além de ser um processo barato e as taxas de produção são altas (NEGRE; SANCHES, 1998).

Dentro dessa perspectiva, foi proposto testar a viabilidade de incorporar resíduo galvânico e vidro sodocálcico em cerâmicas, testando a resistência mecânica, porosidade, absorção de água e retração linear do respectivo material e com isso minimizar um problema ambiental, proporcionando um destino ecologicamente correto a estes resíduos transformando-os em uma matéria prima com viabilidade econômica e, ao mesmo tempo, reduzir a exploração das jazidas naturais e seus impactos ambientais.

\section{EXPERIMENTAL}

\section{MATERIAIS}

Os materiais utilizados no trabalho foram:

(i) Vidro sodocálcico obtido pela moagem de garrafas de vidro;

(ii) Lodo de estação de tratamento de efluentes de uma indústria metal-mecânica da cidade de Santa Maria que utiliza o processo de galvanização;

(iii) Argila branca do tipo faiança.

\section{PRODUÇÃO DOS BLOCOS CERÂMICOS}

Os materiais como lodo galvânico, vidro sodocálcico e argila faiança foram secos na estufa marca DE LEO, modelo SE, na temperatura de $100{ }^{\circ} \mathrm{C}$ por 24 horas. Posteriormente foram moídos separadamente no moinho de bolas marca SERVITECH, modelo CT-241, por um tempo de 10 minutos. Todos os materiais utilizados foram peneirados na peneira ABNT 80 e misturados em formulações que são apresentadas na tabela 1.

Tabela 1 - Porcentagens dos materiais utilizados para as formulações dos blocos cerâmicos.

\begin{tabular}{cccc}
\hline Blocos Cerâmicos & Argila & Lodo Galvânico & Vidro Sodocálcico \\
\hline 10\% Lodo & $75(\%)$ & $10(\%)$ & $15(\%)$ \\
\hline 5\% Lodo & $80(\%)$ & $5(\%)$ & $15(\%)$ \\
$2 \%$ Lodo & $83(\%)$ & $2(\%)$ & $15(\%)$ \\
\hline Branco & $85(\%)$ & 0 & $15(\%)$ \\
\hline \multicolumn{4}{c}{} \\
\hline
\end{tabular}

Após a mistura as formulações foram umidificadas com $8 \%$ de água destilada e realizou-se o peneiramento na peneira ABNT (20) para atomização das partículas. Misturaram-se os materiais com as respectivas formulações apresentados na tabela 2 e foram deixados para homogeneizar na temperatura ambiente durante 24 horas. 
As formulações foram prensados unixialmente a frio na prensa hidráulica marca BOVENAU, modelo P10000, com uma pressão de $30 \mathrm{MPa}$ aplicada por 10 segundos. As peças foram postas sobre uma superfície plana para secar em temperatura ambiente, em seguida foram colocadas na estufa por 24 horas. Sinterizou-se as amostras na mufla marca SANCHIS, na temperatura de $1050{ }^{\circ} \mathrm{C}$, tempo de patamar 2 horas e taxa de aquecimento $5{ }^{\circ} \mathrm{C} / \mathrm{min}$.

As peças foram medidas quanto comprimento, largura e espessura usando paquímetro digital marca MITUTOYO, da peça verde e sinterizada. Produziu-se 10 corpos de prova de cada formulação.

\section{CARACTERIZAÇÕES}

\section{ANALISES MICROESTRUTURAIS}

Difração de Raios X - As amostras foram confeccionadas passando o pós-obtidos por uma peneira com ABNT 325, o pó resultante é colocado no porta-amostra. Posteriormente coloca-se a amostra no difratômetro da marca BRUNKER, modelo D2, com radiação $\mathrm{CuK} \alpha$, configuração de intervalo de ângulo $2 \theta$ entre $5^{\circ}$ e $70^{\circ}$ e incremento de $0,05^{\circ}$ por segundo para análise das fases das amostras.

Espectroscopia no Infravermelho por Transformada de Fourier - Realizou-se a produção das amostras que consiste em moer uma massa de Brometo de Potássio (KBr) e uma massa da amostra, juntando-as/misturando-as, no qual essa massa final é colocada num molde, em seguida é submetida a uma pressão de 7 toneladas dada por uma prensa hidráulica marca FORÇA CARVER, obtendo a forma do molde. Ao final esse sólido com forma do molde é colocado no FTIR marca SHIMADZU, modelo 8300, medidos em modo de transmitância na região de 4000 a $400 \mathrm{~cm}^{-1}$, com resolução de 4 $\mathrm{cm}^{-1}$ com 3 varreduras, obtendo um gráfico para analisar os grupos funcionais da amostra.

\section{PROPRIEDADES MECÂNICAS}

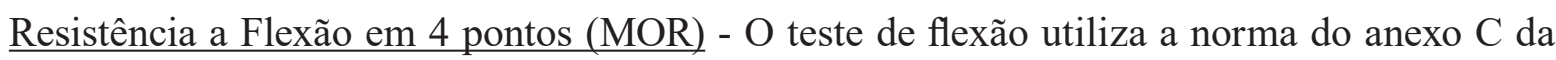
NBR 13818 (1997) que serve para avaliar a resistência mecânica dos corpos de prova utilizando a máquina universal de ensaios marca EMIC. Os corpos de prova são apoiados sobre dois roletes, sofrendo uma força em dois pontos na parte superior e em sua parte inferior sofre uma tensão de tração, o resultado da à força de ruptura do material, para o cálculo do módulo de resistência a flexão utiliza-se a Equação 1.

$$
\operatorname{MOR}(M P a)=\frac{3 F L}{b h^{2}}
$$

Onde:

$\mathrm{F}=$ Força de Ruptura $(\mathrm{N})$;

b e h = Dimensões de Seção Transversal (mm);

$\mathrm{L}=$ Distância entre apoio superior e inferior $(\mathrm{mm})$. 
Absorção de Água - Conforme a ABNT/NBR 15097 (2004) calcula-se a absorção de água em corpos cerâmicos. São medidos quanto ao peso seco $(\mathrm{Ps})$, peso úmido (Pu - peças mergulhadas em água por 24 horas) e submerso ( $\mathrm{Pi}$ - quando o corpo de prova está totalmente submerso na água e com a ajuda de um dispositivo será medido a sua massa). A equação 2 apresenta a fórmula utilizada para calcular a absorção de água dada em porcentagem.

$$
A A(\%)=\frac{P u-P s}{P S} * 100 \%
$$

Onde:

Ps $=$ massa da amostra seca em estufa $(\mathrm{g})$;

$\mathrm{Pu}=$ massa da amostra úmida $(\mathrm{g})$.

Porosidade Aparente - utiliza-se a norma ABNT/NBR 15097 (2004) que denomina a porosidade aparente como percentual volumétrico de porosidade aberta existente na amostra ou a razão entre o volume de poros abertos e o volume da amostra. É calculado pela formula apresentado na equação 3 .

$$
P A(\%)=\frac{P u-P s}{P u-P i} * 100 \%
$$

Onde:

Ps $=$ massa da amostra seca em estufa $(\mathrm{g})$;

$\mathrm{Pu}=$ massa da amostra úmida $(\mathrm{g})$;

$\mathrm{Pi}=$ massa da amostra imersa em água $(\mathrm{g})$.

Retração Linear - Empregando a norma ABNT/NBR 15097 (2004), os corpos de prova são medidos antes e após a queima quanto seu comprimento. A equação 4 demonstra a formula para calcular a retração linear.

$$
R L(\%)=\frac{L s-L q}{L q} * 100 \%
$$

Onde:

$\mathrm{L}_{\mathrm{S}}=$ Comprimento Inicial (mm);

$\mathrm{L}_{\mathrm{Q}}=$ Comprimento da Peça Sinterizada (mm).

\section{TESTE ESTATÍSTICO}

Foram utilizados para a comparação dos resultados do ensaio de flexão o teste ANOVA 1- via, desvio padrão, seguido do teste post-hoc de Tukey para a comparação das médias. Utilizou-se o software Origin. Considerou-se o nível de significância de 5\%. 


\section{RESULTADOS E DISCUSSÃO}

\section{DIFRAÇÃO DE RAIOS X}

Na figura 1 é apresentado o DRX do lodo com tratamento térmico a $800{ }^{\circ} \mathrm{C}$ e sem, denota-se que o lodo in natura demonstra características de cristalinidade alta proveniente da fase PDF 01-070-0909 $\mathrm{Ca}\left(\mathrm{SO}_{4}\right)$ e $\mathrm{PDF}$ 01-073-0161 $\mathrm{Ca}\left(\mathrm{SO}_{3}\right) \cdot\left(\mathrm{H}_{2} \mathrm{O}\right)_{5}$. O lodo depois de calcinado perde a água estrutural apresentando apenas $\mathrm{Ca}\left(\mathrm{SO}_{4}\right)$.

A fase de sulfato de cálcio depois da sinterização a $1100{ }^{\circ} \mathrm{C}$ irá se decompor liberando gases de $\mathrm{SO}_{2}$ e o cálcio ficará incorporado na estrutura. O cálcio pela literatura prove aumento da resistência mecânica e resistência química ao composto.

Figura 1 - Difratograma das amostras de Lodo.

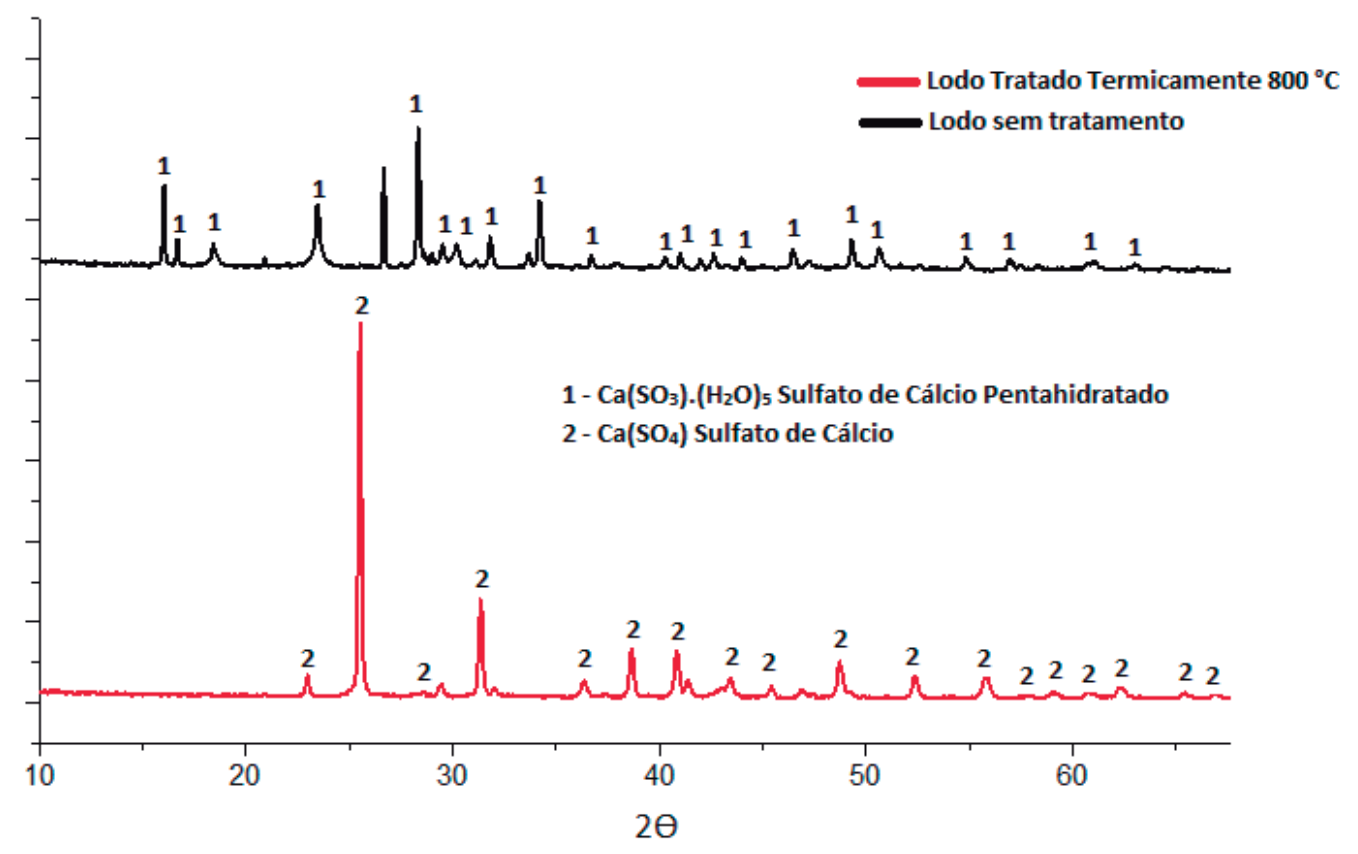

Fonte: Construção da Autora.

A figura 2 demonstra as análises de DRX da argila e das formulações branco (argila $+15 \%$ vidro) e com 10\% lodo galvânico. A fase PDF 01-070-7344 SiO 2 (Quartzo) está presente em todas as amostras. 
Figura 2 - Difratograma das amostras de Argila contendo vidro e lodo.

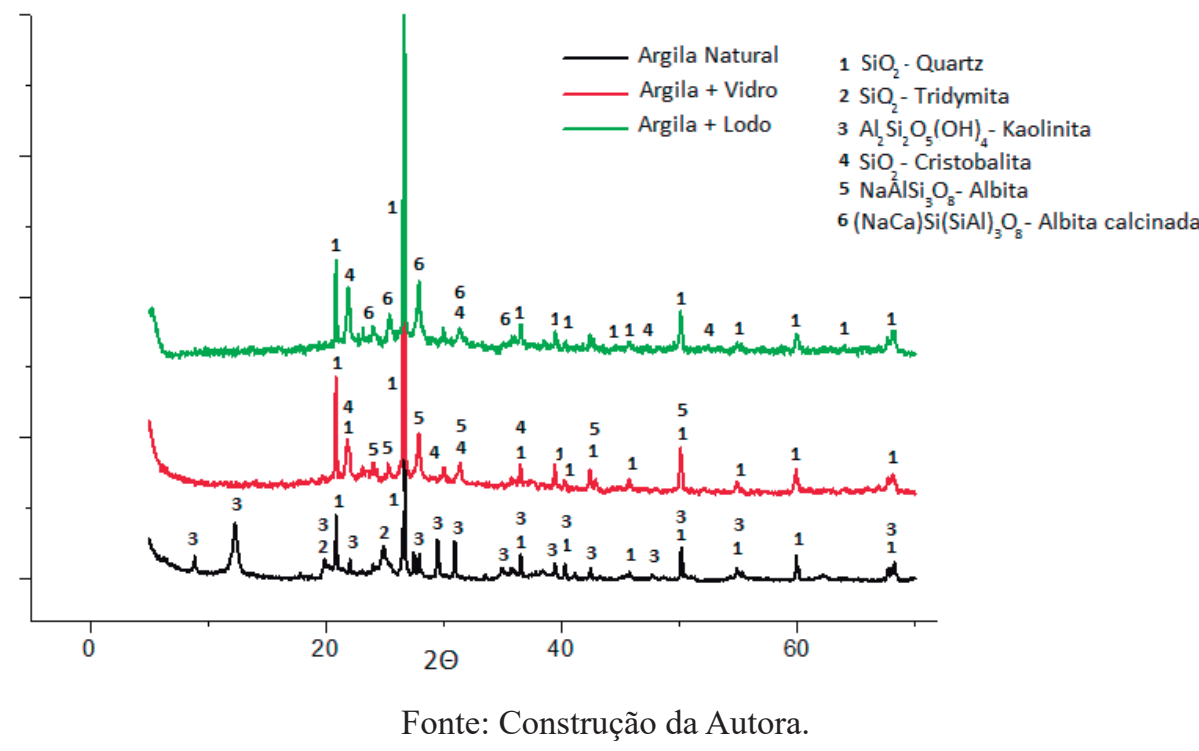

A argila apresentou fases PDF 00-001-0378 $\mathrm{SiO}_{2}$ (Tridymita) e PDF $\mathrm{Al}_{2} \mathrm{Si}_{2} \mathrm{O}_{5}(\mathrm{OH})_{4}$ kaolinita. A amostra com adição de vidro apresentou exibiu fases PDF 00-039-1425 $\mathrm{SiO}_{2}$ (Cristobalita) e PDF 00-009-0466 NaAlSi ${ }_{3} \mathrm{O}_{8}$ (Albita). A amostra com adição de 10\% de lodo exibiu a fase PDF 00-009-0466 $(\mathrm{NaCa}) \mathrm{Si}(\mathrm{SiAl})_{3} \mathrm{O}_{8}$ Albita Calcinada.

\section{ESPECTROSCOPIA NO INFRAVERMELHO POR TRANSFORMADA DE FOURIER}

A figura 3 apresenta os FTIR das amostras do lodo in natura (Ln) e calcinado (Lc) a $800^{\circ} \mathrm{C}$. O lodo (Ln e Lc) apresenta $\mathrm{O}-\mathrm{H}$ na banda de $3450 \mathrm{~cm}^{-1}$ presente na estrutura, observa-se que houve uma diminuição nesta banda na amostra calcinada e a banda de $1370 \mathrm{~cm}^{-1}$ apresentou grupamento químico tipo sulfato, corroborando o resultado do DRX. A banda de $1600 \mathrm{~cm}^{-1}$ denota-se deformação da água estrutural. O número de onda de 1000, 800, 600 é constituído de anéis aromáticos e deformações de C-H. 
Figura 3 - FTIR da amostra de lodo natural e calcinado a $800^{\circ} \mathrm{C}$.

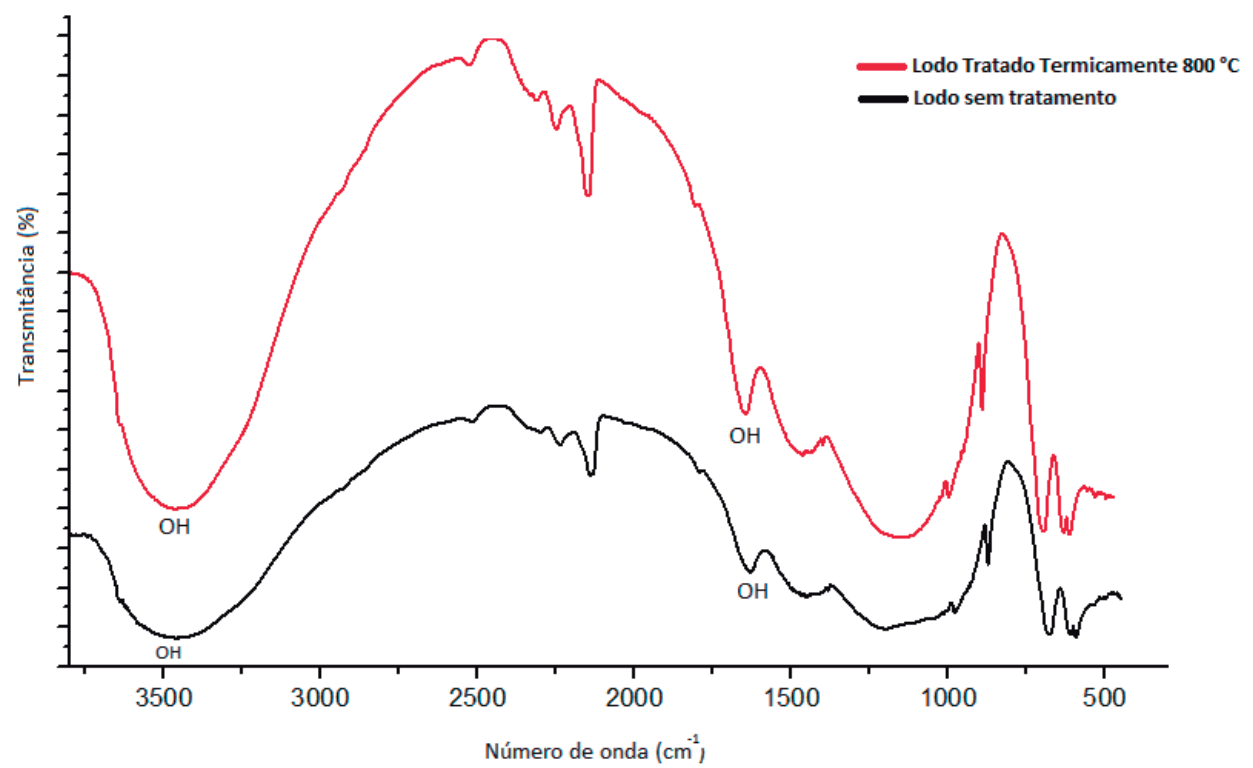

Fonte: Construção da Autora.

\section{MÓDULO DE RESISTENCIA À FLEXÃO EM 4 PONTOS}

Conforme a figura 4 , a adição de $2 \%$ de lodo não apresentou variação significativa na MOR em relação à formulação branca. Entretanto, a incorporação de 5 a $10(\%)$ de lodo apresentou queda na resistência a flexão, diminuindo de 20,2 MPa, das amostras sem lodo e 2\%, para 16,5 e 12,0 MPa para as amostras com 5 e 10\% de lodo, respectivamente. Esta queda da MOR é devido a possibilidade de a decomposição térmica da fase Sulfato de Cálcio ter gerado trincas durante a sinterização.

Figura 4 - Resultado da resistência mecânica a flexão em 4 pontos das amostras.

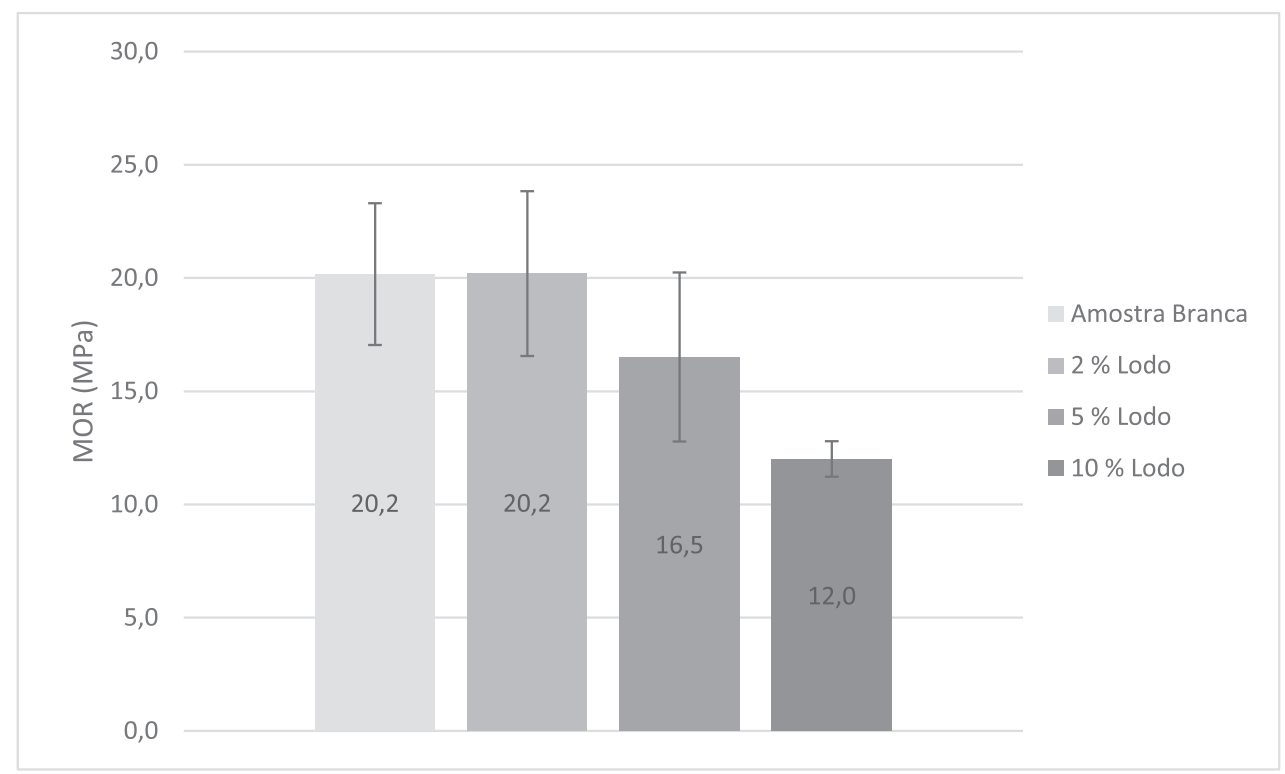

Fonte: Construção da Autora. 
Segundo o teste estatístico ANOVA-1 da MOR as medias das populações dos 4 grupos foram significativamente diferentes ( $\mathrm{p}<0,001$ e $\mathrm{F}=13,7$ ). Porém, apesar de haver a diminuição de cerca de $10 \%$ na média da MOR para a formulação com 5\% de lodo, apenas a formulação com 10\% de lodo galvânico foi estatisticamente diferente considerando o nível de significância de 5\%. Isto é devido ao alto desvio padrão apresentado pelas populações 0,2 e 5\% A tabela 2 apresenta os resultados da análise.

Tabela 2 - Análise estatística da MOR das formulações dos blocos cerâmicos.

\begin{tabular}{ccc}
\hline Amostras comparadas & Probabilidade & Significância \\
\hline $5 \%-10 \%$ & 0,039 & sim \\
\hline $2 \%-10 \%$ & $<0,01$ & $\operatorname{sim}$ \\
\hline $2 \%-5 \%$ & 0,094 & não \\
$0 \%-10 \%$ & $<0,01$ & sim \\
$0 \%-5 \%$ & 0,097 & não \\
$0 \%-2 \%$ & 1 & não \\
\hline
\end{tabular}

Fonte: Construção da Autora.

\section{ABSORÇÃO DE ÁGUA}

O resultado de absorção de água é apresentado na figura 5. Os resultados indicam que a incorporação de lodo de 5 e 10 (\%) tiveram uma maior absorção, de 17,2 \%, comparados as outras amostras (11,2\% e $8,0 \%$ para a amostra branca e $2 \%$ de lodo, repectivamente) corroborando a ideia que a expulsão do sulfato origina a maior porosidade. A diminuição da absorção de água pela amostra $2 \%$ pode ser decorrente da incorporação do cálcio na estrutura da argila (o que é evidenciado pela presença da fase Albita calcinada - $(\mathrm{NaCa}) \mathrm{Si}(\mathrm{SiAl})_{3} \mathrm{O}_{8}$ - na analise de $\left.\mathrm{DRX}\right)$, porém por causa da grande variação dos resultados da amostra branca é difícil afirmar que houve uma variação estatisticamente relevante da média.

Figura 5 - Resultado da absorção de água das amostras.

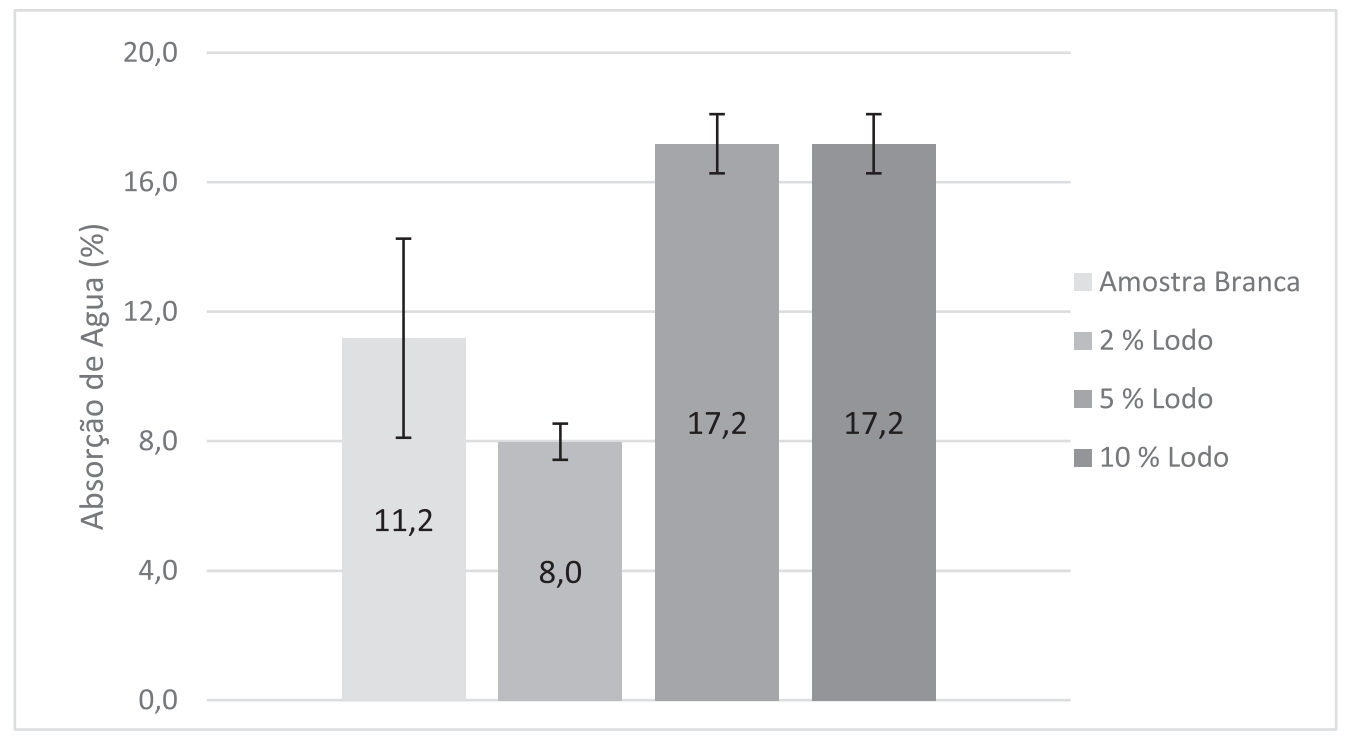

Fonte: Construção da Autora. 


\section{POROSIDADE APARENTE}

A figura 6 demonstra a porosidade aparente das formulações onde se observa que a inserção de $2 \%$ de lodo gerou uma porosidade aparente menor que a branco. Este resultado corrobora a variação observada na AA. Mas é necessário, também, observar que há um grande desvio padrão na amostra $2 \%$, novamente comprometendo a certeza estatística da variação. As demais amostras apresentaram um acentuado aumento da PA (amostra 5\% dobrou em relação a branca e a 10\% teve um aumento de $60 \%$ ). Por apresentarem maiores teores de lodo, por consequência, possuem maiores quantidades de sufaltos a serem decompostos, justificando a elevação na porosidade aparente.

Figura 6 - Resultado da porosidade aparente das amostras.

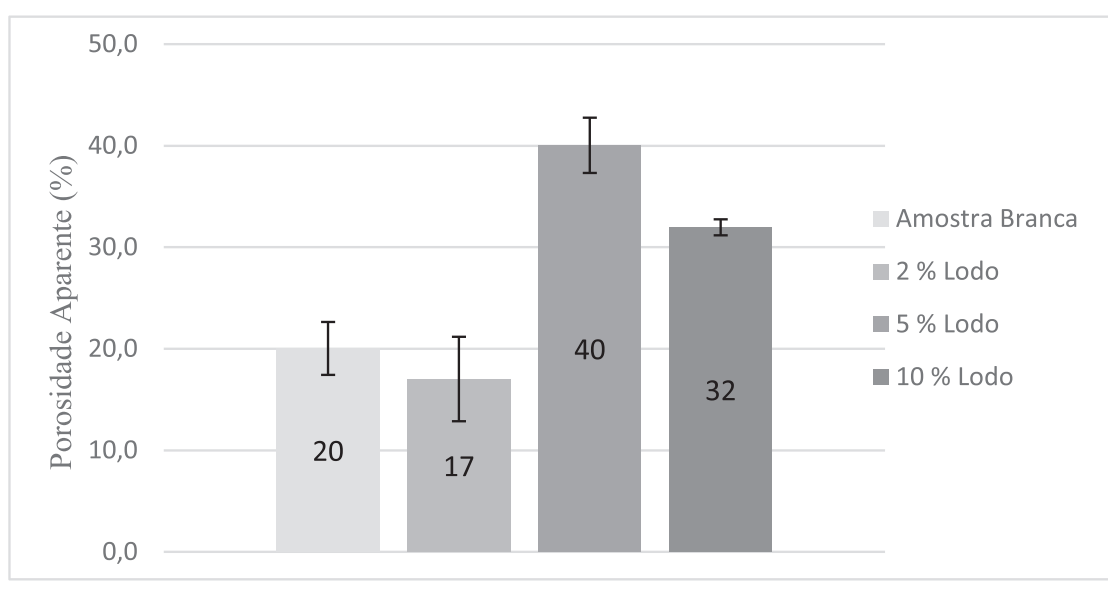

Fonte: Construção da Autora.

\section{RETRAÇÃO LINEAR}

O gráfico da figura 7 demonstra que a retração linear não obteve uma variação significativa levando a crer que as variações em MOR, PA e AA não se relacionam aos valores de retração.

Figura 7 - Resultado da retração linear das amostras.

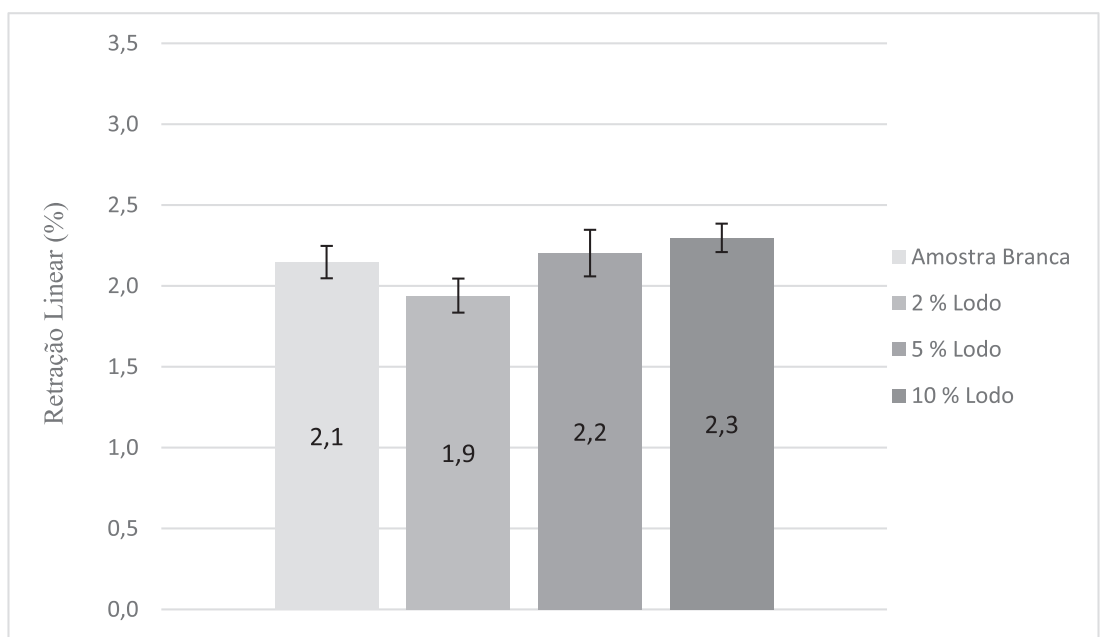

Fonte: Construção da Autora. 


\section{CONCLUSÃO}

Foi possível incorporar o resíduo na formulação cerâmica, em quantidades de até $2 \%$ sem ter uma variação apreciável de resistência mecânica comparado com a formulação sem incorporação de lodo $(\mathrm{MOR}=20 \mathrm{MPa})$. Esta formulação também apresentou uma diminuição na absorção de água e porosidade aparente, comparando a amostra branca. É possível que a argila tenha incorporado parte do cálcio presente no lodo. As formulações com 5 e 10\% de lodo tiveram uma diminuição significativa na resistência e um aumento na porosidade aparente e na absorção de água. Esta piora nas propriedades, muito possivelmente, é devida a decomposição do sulfato de cálcio durante a sinterização. Esta decomposição além de gerar poros pode ter criado trincas que diminuam ainda mais a resistência mecânica a flexão. Não foi observada uma variação significativa na retração linear. Dessa forma é possível visualizar um potencial de utilização do lodo galvânico como matéria prima da indústria cerâmica, mas ainda mostra-se necessário a realização de ensaio de lixiviação e solubilização nos blocos cerâmicos para ver se o resíduo é realmente imobilizado na estrutura cerâmica.

\section{AGRADECIMENTOS}

Agradeço a Universidade Franciscana pelos materiais e equipamento utilizados.

\section{REFERÊNCIAS}

ASSOCIAÇÃO BRASILEIRA DE NORMAS TÉCNICAS. NBR 10004: Classificação de Resíduos Sólidos. Rio de Janeiro, p. 1-77, 2004.

ASSOCIAÇÃO BRASILEIRA DE NORMAS TÉCNICAS. NBR 13818: Placas Cerâmicas para Revestimento- Especificação e Métodos de Ensaio. Rio de Janeiro, p. 1-78, 1997.

ASSOCIAÇÃO BRASILEIRA DE NORMAS TÉCNICAS. NBR 15097: Aparelhos Sanitários de Material Cerâmico- parte 1: Requisitos e Métodos de Ensaios. Rio de Janeiro. p. 1-65, 2004.

DA ROCHA, R. D. C; ZOREL, H. E; LANDO, T. Utilização de planejamento experimental no estudo para imobilização de lodo galvânico em cerâmica vermelha para minimização de impactos ambientais; Universidade Tecnológica Federal do Paraná, Via do Conhecimento, Pato Branco, PR, Brasil, 2017. 
NEGRE, F; SANCHES, E. Avanços no processamento de pós atomizados para a fabricação de revestimentos cerâmicos. Cerâmica Industrial. v. 3, n. 2, 1998.

SANTOS, W.J. Caracterização de vidros planos transparentes comerciais. Scientia Plena, v. 5, n. 2, p. 1-4, 2009.

TANAUE, B; CLAUDIA, A; BEZERRA, M; DEIVID; CAVALHEIRO, L; CRISTIANE, P. L. Lixo Eletrônico: Agravos a Saúde e ao Meio Ambiente. Faculdade Anhanguera de Bauru. SP, Brasil, 2015. 